\title{
Comparison of static friction with self-ligating, modified slot design and conventional brackets
}

\author{
Raquel Morais CASTRO', Perrin SMITH NETO², Martinho Campolina Rebello HORTA3, Matheus Melo PITHON ${ }^{4}$, \\ Dauro Douglas OLIVEIRA ${ }^{5}$
}

\begin{abstract}
1- Former resident in Orthodontics, Pontifical Catholic University of Minas Gerais, Belo Horizonte, MG, Brazil.
2- PhD, Mechanical Engineering, University of São Paulo; Professor, Mechanical Engineering, Pontifical Catholic University of Minas Gerais, Belo Horizonte, MG, Brazil.

3- DDS, PhD, Pathology, Federal University of Minas Gerais; Associate Professor and Dean of Graduate Studies, Department of Dentistry, Pontifical Catholic University of Minas Gerais, Belo Horizonte, MG, Brazil.

4- DDS, PhD, Orthodontics, School of Dentistry, Federal University of Rio de Janeiro; Professor of Orthodontics, Southwest Bahia State University - UESB, Jequié, BA, Brazil.

5- DDS, PhD, Orthodontics, School of Dentistry, Federal University of Rio de Janeiro; Program Director of Orthodontics, Pontifical Catholic University of Minas Gerais, Belo Horizonte, MG, Brazil.
\end{abstract}

Corresponding address: Dauro Douglas Oliveira - Pontifícia Universidade Católica de Minas Gerais - Mestrado em Odontologia - Av. Dom José Gaspar, 500 - Prédio 46 - Sala 106 - Belo Horizonte - MG - Brazil - 30535-610 - Phone: 55 - 31 - 3319-4414 - Fax: 55 - 31 - $3319-4415$ - e-mail: dauro@pucminas.br

Submitted: January 20, 2013 - Modification: May 01, 2013 - Accepted: May 17, 2013

\section{ABSTRACT}

\begin{abstract}
O bjective: To compare the static frictional forces generated at the bracket/wire interface of stainless steel brackets with different geometries and angulations, combined with orthodontic wires of different diameters. Material and Methods: The frictional forces were evaluated with three different types of metal brackets: a passive self-ligating (SmartClip ${ }^{\mathrm{TM}}$, 3M/Unitek, Monrovia, USA), with a modified slot design (Mini Uni Twin ${ }^{\mathrm{TM}}, 3 \mathrm{M} /$ Unitek, Monrovia, USA) and conventional (Kirium, Abzil, São José do Rio Preto, Brazil). The samples were mounted in a testing device with three different angulations and tested with 0.014" and 0.018" stainless steel wires (American Orthodontics, Sheboygan, USA). The static frictional force was measured using a universal testing machine (DL 500, EMIC ${ }^{\circledR}$, São José dos Pinhais, Brazil) with a crosshead speed of $1 \mathrm{~mm} / \mathrm{min}$. Statistical analysis was performed by two-way ANOVA followed by Bonferroni's post hoc test. Results: There was a significant difference $(p<0.05)$ in static friction when the three types of brackets were tested with the same wire size. The wire diameter influenced friction only when the brackets had a $10^{\circ}$ angulation $(p<0.05)$. The angulation influenced friction $(p<0.05)$ when the brackets were associated with a 0.018 " wire. Conclusion: Brackets with a modified slot design showed intermediate static frictional force values between the conventional and self-ligating brackets tested.
\end{abstract}

Key words: Friction. Orthodontics. Orthodontic brackets.

\section{INTRODUCTION}

Friction is defined as a force that opposes the tendency of motion of a body in contact with a surface. It acts tangent to the contact surfaces and arises when one surface tends to slide in relation to the other or when they are actually moving ${ }^{4,15}$. Friction can be divided into Static (SF) and Kinetic friction $(\mathrm{KF})^{17,19}$. SF is the smallest force needed to initiate a movement of a body which was at rest and Kinetic friction (KF) is a force that opposes the sliding of a body already in movement. In Orthodontics,
$\mathrm{KF}$ is irrelevant because the movement of the tooth along the wire is not continuous, occurring in a sequence of intermittent small movements ${ }^{2}$.

The orthodontic tooth movement registered with sliding mechanics occurs in an alternating series of crown inclination and root uprighting towards the applied force ${ }^{1,12}$. When a traction force is applied to the bracket, the tooth's crown inclines until the wire contacts the edge of the slot, causing bends between the wire and bracket (binding effect), thus increasing friction ${ }^{10,13}$. According to Thorstenson and Kusy $^{18}$ (2001), binding effect is defined as part of 
the resistance to sliding that occurs when the wire is angulated in the slot without presenting plastic deformation. Both the amount of tooth angulation and the stiffness of the wire may influence the binding effect.

The manufactures of orthodontic materials have made several attempts to develop products that generate lower amounts of friction at the bracket/ wire interface such as the self-ligating brackets (SLB). These brackets do not require the use of ligatures to maintain the wire inside the slot. The manufacturers advocate that SLB present lower levels of friction and allow easier insertion and removal of the archwires, thus reducing chair time ${ }^{3,16}$. Some authors suggest that friction reduction would contribute to shorten the orthodontic treatment duration. Furthermore, other researchers reported that SLB are less uncomfortable for the patients and easier to be hygienized ${ }^{6,16}$. However, these features are not unanimously accepted and SLB also hold the disadvantage of having significantly higher costs than conventional brackets (CB).

Therefore, other low friction systems have been developed such as CB associated to modified elastomeric ligatures or brackets with modified slot design (MSDB). The manufacturers claim that these systems generate lower levels of friction without having the higher costs of self-ligating brackets. To date, there is a lack of studies that investigated if MSDB may be considered a viable alternative to SLB. Therefore, the aim of this study was to compare the static frictional force generated at the bracket/wire interface with passive SLB and MSDB, using conventional brackets as controls. In addition to test the hypothesis that changes in design of conventional brackets reduces the coefficient of friction.

\section{MATERIAL AND METHODS}

Three types of stainless steel brackets were evaluated: passive self-ligating (SmartClip ${ }^{\mathrm{TM}}$, 3M/ Unitek, Monrovia, California, USA); with a modified slot design (Mini Uni Twin ${ }^{\mathrm{TM}}$, 3M/Unitek, Monrovia, CA) and conventional (Kirium, 3M/Abzil, São José do Rio Preto, SP, Brazil). All brackets tested were for the right maxillary central incisor. The SmartClip ${ }^{\mathrm{TM}}$ samples presented a $0.022 \times 0.028^{\prime \prime}$ slot in MBT prescription ( $4^{\circ}$ angulation and $17^{\circ}$ torque) and the others had a $0.022 \times 0.030^{\prime \prime}$ slot in Roth prescription ( $5^{\circ}$ angulation and $12^{\circ}$ torque) (Figure 1 ). The Mini Uni Twin ${ }^{\mathrm{TM}}$ and Kirium brackets were associated to conventional gray elastomeric ligatures (Unistick Ligatures $^{\mathrm{TM}}$, American Orthodontics, Sheboygan, WI). Stainless steel round $0.014^{\prime \prime}$ and $0.018^{\prime \prime}$ (American Orthodontics, Sheboygan, WI, USA) were the wires tested.

All tests and samples preparation were performed by the same operator. In order to avoid the presence of oily substances or impurities that could interfere with the results, the brackets and wires were previously cleaned with gauze soaked in $70 \%$ ethyl-alcohol.

A testing apparatus consisting of two aluminum plates was fabricated to simulate the orthodontic sliding mechanics. During the tests, the brackets remained at rest and the wire slid along the bracket slot. One aluminum plate was directly connected to the load cell attached to the superior part of the universal testing machine (EMIC ${ }^{\circledR}$ DL 500, São José dos Pinhais, PR, Brazil) and the other was fixed to the inferior part by a device that allowed anteroposterior adjustments, thus enabling the passive alignment of the wire in the brackets slot preventing any angulation between the plates. The parallelism between the upper and lower aluminum plates was visually checked when they were approximated with a dial indicator with centesimal resolution (Mitutoyo, Santo Amaro, SP, Brazil).

The upper aluminum plate presented a hex head screw to which a conventional bracket was bonded with instant cyanoacrylate ester based adhesive (Super Bonder ${ }^{\circledR}$, Loctite Henkel, São Paulo, SP, Brazil). This screw had a groove to guide the bracket positioning because it had to be placed collinearly to the three brackets of the lower plate. Due to the different profiles of the three types of brackets tested, the aluminum plates were changed according to the group being tested.

The lower aluminum plate presented three hex

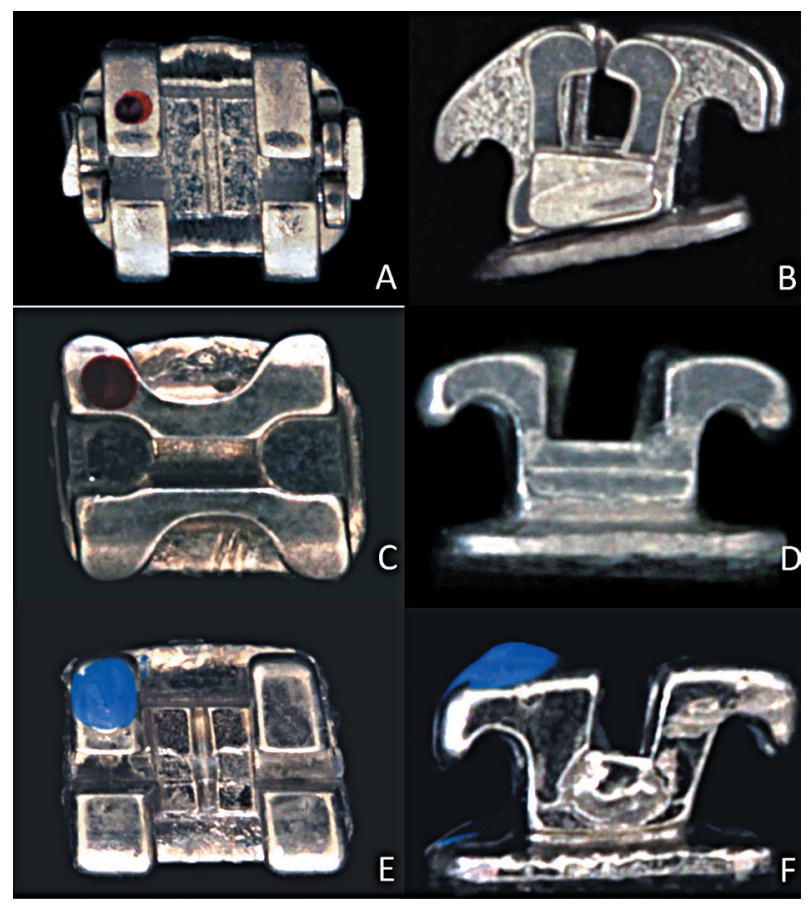

Figure 1- Brackets evaluated. (A-B) Passive self-ligating bracket. (C-D) Bracket with modified slot design. (E-F) Conventional bracket 
head screws with a needle that was adapted to the screws to indicate the bracket angulation at $0^{\circ}, 5^{\circ}$ and $10^{\circ}$. There was a winged nut in the back of the aluminum plate that allowed locking and unlocking of the screw in order to regulate the angulation. On each screw, a bracket was bonded with instant cyanoacrylate ester based adhesive (Super Bonder ${ }^{\circledR}$, Loctite Henkel, São Paulo, SP, Brazil). A straight groove was made on the center of the screws to facilitate the correct placement of the brackets. All brackets were bonded at the center of the screw and aligned one in relation to the others.

Only the middle bracket had the angulation changed (Figure 2), simulating a tooth inclination in relation to the adjacent well-positioned teeth. The distance between the centers of two adjacent brackets was established at $8 \mathrm{~mm}$ to simulate the maxillary central incisors interbracket distance. In order to guarantee accuracy and reproducibility in the positioning of all brackets tested, a U-shaped bonging guide was constructed with 0021 "x0025" stainless steel wire. This device was inserted in the brackets' slots and in the holes located on the extremities of the lower plate simultaneously. This procedure ensured that the three brackets were properly aligned and the entry angle of the wire was $0^{\circ}$.

Each combination of bracket/wire or bracket/ wire/ligature was submitted to three consecutive tests, using the same wire and angulation. After the sample was tested with the middle bracket

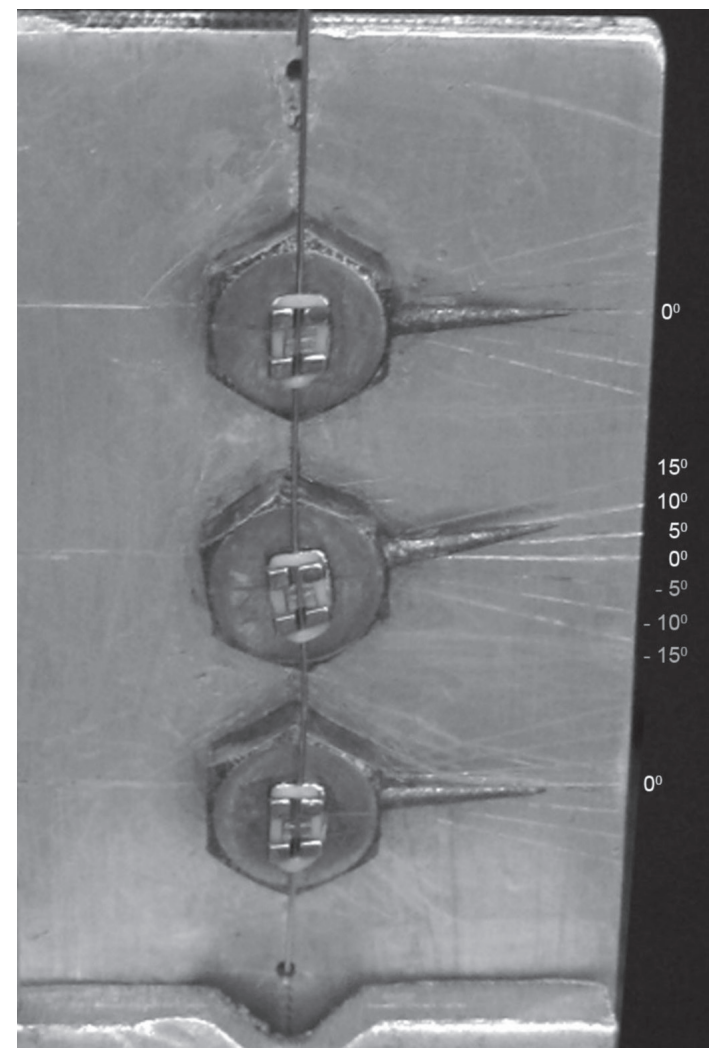

Figure 2- Middle bracket positioned with $10^{\circ}$ of angulation positioned at $0^{\circ}$, another wire was inserted and the middle bracket was set at $5^{\circ}$. After three consecutive tests with this angulation, the same procedure was repeated with $10^{\circ}$ of angulation. The same set of brackets underwent nine tests only by varying the angulations and the wires of the sample. Each test group was comprised of 10 samples with a total of 30 tests in each group.

During the Mini Uni Twin ${ }^{\mathrm{TM}}$ and Kirium sample preparation, a ligature insertion device was used to standardize the amount of extension of the elastomeric ligatures (Straight-Shooter ${ }^{\circledR}$, TP Orthodontics, La Porte, IN, USA). The universal testing machine was calibrated following the manufacturer's instructions coupled to a $5000 \mathrm{~N}$ load cell and used with a cross-head speed of 1 $\mathrm{mm} / \mathrm{min}$.

The frictional force was obtained by the median of three consecutive measurements in each tested group. The D'Agostino and Pearson test was applied and showed that the data had a normal distribution. Differences among groups were analyzed by twoway ANOVA followed by Bonferroni's post hoc test. The significance level was established at $5 \%$. Statistical analysis was performed by GraphPad Prism 5.00 (GraphPad Software, San Diego, California, USA).

\section{RESULTS}

There was a statistically significant difference $(p<0.05)$ of frictional forces among the three brackets tested with the same angulation and wire size (Table 2). The conventional brackets showed higher mean friction values than the brackets with a modified slot design $(p<0.05)$. The frictional values recorded with SLB were significantly lower than those observed with the other two types of brackets tested $(p<0.05)$.

The values of the tests performed with $0.014^{\prime \prime}$ archwire showed that the increase in angulation did not significantly ( $p>0.05)$ affect the friction of any of the groups tested. However, when the samples were tested with the 0018" archwire, changing the angulation of the middle bracket from $0^{\circ}$ to $10^{\circ}$ significantly increased $(p<0.05)$ the static frictional forces recorded (Table 1 ).

The type of bracket significantly influenced the SF values registered with the middle bracket angulated at $0^{\circ}$ and $5^{\circ}(\mathrm{p}<0.05$; Table 2$)$. However, there was no statistically significant difference ( $p>0.05$; Table 1) on SF between the 0.014" and $0.018^{\prime \prime}$ archwires when booth of these angulations were tested. Conversely, when the middle bracket was positioned with $10^{\circ}$ of angulation, both the type of bracket and the wire size significantly affected $(p<0.05)$ the amount of static friction registered (Table 1 and Table 2). 
Table 1- Mean and standard deviation of frictional force $(\mathrm{N})$ between different types of brackets, angulations and gauge: a comparison between angulation and wire gauge

\begin{tabular}{|c|c|c|c|c|c|}
\hline & & $0^{\circ}$ & $5^{\circ}$ & $10^{\circ}$ & $p^{*}$ value \\
\hline \multirow{3}{*}{$\begin{array}{l}\text { Conventional } \\
\text { bracket }\end{array}$} & $0.014 "$ & $2.93 \pm 1.02$ & $2.72 \pm 0.86$ & $3.21 \pm 0.57$ & $n \cdot s^{a, b, c}$ \\
\hline & $0.018 ”$ & $2.79 \pm 0.86$ & $3.14 \pm 0.94$ & $4.86 \pm 0.93$ & n. $s^{a} / p<0.05^{b, c}$ \\
\hline & $\mathrm{p}^{*}$ value & $n \cdot s^{d}$ & $\mathrm{n} . \mathrm{s}^{\mathrm{d}}$ & $p<0.05^{d}$ & \\
\hline \multirow{3}{*}{$\begin{array}{l}\text { Bracket with } \\
\text { a modified slot } \\
\text { design }\end{array}$} & $0.014 "$ & $1.69 \pm 0.13$ & $1.67 \pm 0.20$ & $1.74 \pm 0.20$ & $n \cdot s^{a, b, c}$ \\
\hline & $0.018 "$ & $1.91 \pm 0.26$ & $1.83 \pm 0.24$ & $3.24 \pm 0.60$ & $n . s^{a} / p<0.05^{b, c}$ \\
\hline & $\mathrm{p}^{*}$ value & $n \cdot s^{d}$ & $n \cdot s^{d}$ & $p<0.05^{d}$ & \\
\hline \multirow{3}{*}{$\begin{array}{c}\text { Self-ligating } \\
\text { bracket }\end{array}$} & $0.014 "$ & $0.17 \pm 0$ & $0.17 \pm 0$ & $0.37 \pm 0.07$ & $n \cdot s^{a, b, c}$ \\
\hline & $0.018 ”$ & $0.17 \pm 0$ & $0.37 \pm 0.21$ & $1.32 \pm 0.50$ & $\mathrm{n} . \mathrm{s}^{\mathrm{a}} / \mathrm{p}<0.05^{\mathrm{b}, \mathrm{c}}$ \\
\hline & $\mathrm{p}^{*}$ value & $n \cdot s^{d}$ & $n . s^{d}$ & $p<0.05^{d}$ & \\
\hline
\end{tabular}

*p values were obtained by two way ANOVA followed by Bonferroni's post hoc test.

a $0^{\circ}$ versus $5^{\circ} ;{ }^{\text {b }} 0^{\circ}$ versus $10^{\circ} ;{ }^{c} 5^{\circ}$ versus $10^{\circ} ;{ }^{\text {d }} 0.014$ " versus 0.018 "; n.s=not significant.

Table 2- Mean and standard deviation of frictional force $(\mathrm{N})$ between different types of brackets, angulations and gauge: a comparison between different types of brackets

\begin{tabular}{cccccc}
\hline & & $\begin{array}{c}\text { Conventional } \\
\text { bracket }\end{array}$ & $\begin{array}{c}\text { Bracket with } \\
\text { a modified slot } \\
\text { design }\end{array}$ & $\begin{array}{c}\text { Self-ligating } \\
\text { bracket }\end{array}$ & $p^{*}$ value \\
\hline $0^{\circ}$ & $0.014^{\prime \prime}$ & $2.93 \pm 1.02$ & $1.69 \pm 0.13$ & $0.17 \pm 0$ & $p<0.05^{\mathrm{a}, \mathrm{b}, \mathrm{c}}$ \\
& $0.018^{\prime \prime}$ & $2.79 \pm 0.86$ & $1.91 \pm 0.26$ & $0.17 \pm 0$ & $\mathrm{p}<0.05^{\mathrm{a}, \mathrm{b}, \mathrm{c}}$ \\
$5^{\circ}$ & $0.014^{\prime \prime}$ & $2.72 \pm 0.86$ & $1.67 \pm 0.20$ & $0.17 \pm 0$ & $\mathrm{p}<0.05^{\mathrm{a}, \mathrm{b}, \mathrm{c}}$ \\
& $0.018^{\prime \prime}$ & $3.14 \pm 0.94$ & $1.83 \pm 0.24$ & $0.37 \pm 0.21$ & $\mathrm{p}<0.05^{\mathrm{a}, \mathrm{b}, \mathrm{c}}$ \\
\hline $10^{\circ}$ & $0.014 "$ & $3.21 \pm 0.57$ & $1.74 \pm 0.20$ & $0.37 \pm 0.07$ & $\mathrm{p}<0.05^{\mathrm{a}, \mathrm{b}, \mathrm{c}}$ \\
& $0.018^{\prime \prime}$ & $4.86 \pm 0.93$ & $3.24 \pm 0.60$ & $1.32 \pm 0.50$ & $\mathrm{p}<0.05^{\mathrm{a}, \mathrm{b}, \mathrm{c}}$ \\
\hline
\end{tabular}

*p values were obtained by two way ANOVA followed by Bonferroni's post hoc test

a Conventional bracket versus bracket with changed groove geometry; ${ }^{\mathrm{b}}$ Conventional bracket versus self-ligating bracket;

${ }^{\mathrm{c}}$ bracket with changed groove geometry versus self-ligating bracket

\section{DISCUSSION}

The influence of certain materials in the frictional force during orthodontic treatment has been a frequently discussed topic in contemporary orthodontics. In recent years, manufacturers of orthodontic materials have suggested that the use of self-ligating brackets provides better clinical results than those obtained with conventional brackets ${ }^{1}$. Chair time reduction and shortened treatment duration have been mentioned as potential advantages of self-ligating brackets. These supposed advantages must be investigated impartially, whereas the cost of self-ligating brackets is significantly higher than conventional brackets $^{14}$.

Do these advantages justify the increased costs of SLBs? Is there another type of bracket that would reduce friction and present lower costs to orthodontists? Are the modified slot design brackets as efficient as SLBs to reduce friction? Could they be considered a viable alternative to SLBs? This study compared the static frictional observed with SLBs, MSDBs and CBs simulating the presence of inclined maxillary central incisors.

In Orthodontics, during the sliding mechanics, the movement of the tooth along the wire is not continuous; it occurs in a sequence of stops, close to the equilibrium ${ }^{2}$. Therefore, this study reported only the static frictional force generated between the bracket and orthodontic archwire. Some research ${ }^{1,8}$ compared the friction of passive and active self-ligating brackets and concluded that the passive SLB were associated with lower frictional forces. Therefore, the only type of SLB tested in the present study was the passive ones.

Among the brackets tested in this study, the $\mathrm{CB}$ showed higher values of static friction higher than the MSDB. This finding may be due to the rounded inner corners of the modified slot design displayed by the Mini Uni Twin ${ }^{T M}$ brackets. Thus, when the orthodontic force was applied to these brackets, the binding effect may have been smaller than that 
registered with the conventional bracket tested.

The self-ligating bracket showed the lowest level of static friction when compared to the others. The manufacturers claim that SLB are more efficient and shorten treatment time due to the reduced friction compared to conventional brackets ${ }^{1}$. Krishnan, Kalathil and Abraham ${ }^{9}$ (2009) demonstrated that both static and kinetic friction was smaller in active and passive SLBs compared to conventional brackets, corroborating to the results of the present work.

The tie configuration of the elastomeric ligatures is another factor that may influence the amount of friction generated during sliding mechanics. According to Hain, Dhopatkar and Rock ${ }^{7}$ (2003), a figure-8 tie configuration increased the level of friction in all bracket systems tested. In the present study, a ligature insertion device was used to standardize the amount of extension of each elastomeric ligatures used in the tests.

Among the biological factors that may influence friction in Orthodontics, the presence of saliva must be considered. It acts as a lubricant, reducing the static friction independent of the bracket system used $^{7}$. This variable was not evaluated in this study and all tests were carried out in a humidity-free environment. Further research must be carried out in the presence of humidity in order to evaluate the effects on static friction with MSDBs.

The amount of debris and surface roughness of the archwire is directly related to increased friction between the bracket and wire during the sliding mechanics ${ }^{11}$. In order to avoid the presence of oily substances or impurities and thus eliminate this variable, the brackets and wires tested were cleaned by rubbing with gauze soaked in $70 \%$ ethyl alcohol .

The role of friction in Orthodontics has received a lot attention because of the intense marketing campaigns developed by the various orthodontic companies that manufacture self-ligating brackets ${ }^{2}$. However, the presence of friction may be important in the same stages of the orthodontic treatment. During leveling and alignment, lower levels of friction may be interesting to increase treatment efficiency. However, during the finishing phase of the orthodontic therapy, the presence of friction at the bracket/archwire interface is indispensable to obtain the correct three-dimensional positioning of the teeth.

Despite the several studies about self-ligating brackets published in the past decade, there isn't enough evidence to support their use as the golden standard of orthodontic brackets ${ }^{5}$. According to the results of this study, brackets with a modified slot design such as rounded inner corners may be as effective as SLBs in reducing friction without presenting the significantly higher costs associated with any SLB available in the market. However, further studies should be performed to evaluate the performance of MSDBs in other relevant clinical situations such as torqueing expression during the final stages of the orthodontic treatment.

\section{CONCLUSIONS}

The hypothesis was confirmed: SLBs showed the lowest level of static friction among the types of brackets tested and the brackets with a modified slot design presented static frictional force significantly smaller than the conventional brackets in all situations tested and they may be considered as a viable alternative to self-ligating brackets.

\section{REFERENCES}

1- Budd S, Daskalogiannakis J, Tompson BD. A study of the frictional characteristics of four commercially available self-ligating bracket systems. Eur J Orthod. 2008;30(6):645-53.

2- Burrow SJ. Friction and resistance to sliding in orthodontics: a critical review. Am J Orthod Dentofacial Orthop. 2009;135 (4):442-7.

3- Cacciafesta V, Sfondrini MF, Ricciardi A, Scribante A, Klersy C, Auricchio F. Evaluation of friction of stainless steel and esthetic self-ligating brackets in various bracket-archwire combinations. Am J Orthod Dentofacial Orthop. 2003;124(4):395-402.

4- Fidalgo TK, Pithon MM, Maciel JV, Bolognese AM. Friction between different wire bracket combinations in artificial saliva - an in vitro evaluation. J Appl Oral Sci. 2011;19(1):57-62.

5- Fleming PS, Johal A. Self-ligating brackets in orthodontics. A systematic review. Angle Orthod. 2010;80(3):575-84.

6- Franchi L, Baccetti T, Camporesi M, Barbato E. Forces released during sliding mechanics with passive self-ligating brackets or nonconventional elastomeric ligatures. Am J Orthod Dentofacial Orthop. 2008;133(1):87-90.

7- Hain M, Dhopatkar A, Rock P. The effect of ligation method on friction in sliding mechanics. Am J Orthod Dentofacial Orthop. 2003;123(4):416-22.

8- Huang TH, Luk HS, Hsu YC, Kao CT. An in vitro comparison of the frictional forces between archwires and self-ligating brackets of passive and active types. Eur J Orthod. 2012;34(5):625-32.

9- Krishnan M, Kalathil S, Abraham KM. Comparative evaluation of frictional forces in active and passive self-ligating brackets with various archwire alloys. Am J Orthod Dentofacial Orthop. 2009;136(5):675-82.

10- Loh KW. Rapid tooth movement with a low-force, low-friction bracket system. J Clin Orthod. 2007;41(8):451-7.

11- Marques IS, Araújo AM, Gurgel JA, Normando D. Debris, roughness and friction of stainless steel archwires following clinical use. Angle Orthod. 2010;80(3):521-7.

12- Nováčková S, Marek I, Kamínek M. Orthodontic tooth movement: bone formation and its stability over time. Am J Orthod Dentofacial Orthop. 2011;139(1):37-43.

13- Ogura M, Yamagata K, Kubota S, Kim JH, Kuroe K, Ito G. Comparison of tooth movements using Friction-Free and preadjusted edgewise bracket systems. J Clin Orthod. 1996;30(6):325-30.

14- Pacheco MR, Oliveira DD, Neto PS, Jansen WC. Evaluation of friction in self-ligating brackets subjected to sliding mechanics: an in vitro study. Dental Press J Orthod. 2011;16:107-15.

15- Rossouw PE. Friction: an overview. Semin Orthod. 2003;9:218-22.

16- Shivapuja PK, Berger J. A comparative study of conventional ligation and self-ligation bracket systems. Am J Orthod Dentofacial Orthop. 1994;106(5):472-80. 
17- Smart FM. Kinetic friction. Am J Orthod Dentofacial Orthop. $2004 ; 125 ;(2): 17 A$.

18- Thorstenson GA, Kusy RP. Resistance to sliding of self-ligating brackets versus conventional stainless steel twin brackets with second-order angulation in the dry and wet (saliva) states. Am J Orthod Dentofacial Orthop. 2001;120(4):361-70.

19- Yanase Y, Ioi H, Uehara M, Hara A, Nakata S, Nakasima A, et al. Comparison of the kinetic frictional force between conventional plastic brackets with thermoplastic low-friction module ligation and self-ligating brackets. World J Orthod. 2009;10(3):220-3. 